\title{
An in situ cell for transmission EXAFS measurements on catalytic samples
}

\author{
F.W.H. Kampers
}

Laboratory for Inorganic Chemistry and Catalysis, Eindhoven University of Technology, P. O. Box 513, $5600 \mathrm{MB}$ Eindhoven, The Netherlands

\section{T.M.J. Maas}

Technological Design and Development Group, Eindhoven University of Technology, P. O. Box 513, $5600 \mathrm{MB}$ Eindhoven, The Netheriands

J. van Grondelle

Laboratory for Irorganic Chemistry and Catalysis, Eindhoven University of Technology, P. O. Box 513, 5600MB Eindhoven, The Netherlands

\section{P. Brinkgreve}

Technological Design and Development Group, Eindhoven University of Technology, P. O. Box 513, 5600 MB Eindhoven, The Netherlands

D. C. Koningsberger ${ }^{3}$

Laboratory for Inorganic Chemistry and Catalysis, Eindhoven University of Technology, P. O. Box 513, 5600 MB Eindhoven, The Netherlands

(Received 2 February 1989; accepted for publication 6 March 1989)

\begin{abstract}
An in situ cell suitable for transmission EXAFS measurements on catalytic samples is described. The cell can be used for catalyst pretreatments in various atmospheres (including $\mathrm{H}_{2}, \mathrm{H}_{2} \mathrm{~S}, \mathrm{O}_{2}$ and $\mathrm{CO}$ ) in a temperature range upto $700 \mathrm{~K}$. The sample is heated by conducting heat from an external heater to the sample. During measurement the samples can be cooled down to $77 \mathrm{~K}$ by conducting heat from the sample to an external liquid nitrogen container. During the pretreatment and the measurement $a$ waterflow through the body of the cell keeps certain crucial parts from overheating or icing up. To avoid radiation leaks in powdery samples these samples are pressed in a selfsupporting wafer and held in a disk-shaped sampleholder. Tests by various catalytic groups have proven the suitability of the design.
\end{abstract}

\section{INTRODUCTION}

EXAFS in the last decade has become a popular tool in research of heterogeneous catalytic systems where small particles of chemically active elements are dispersed on a suitable support. The specific requirements for these experiments necessitate special in situ cells in which the experiments can be performed.

To study a catalytic sample under reaction conditions it has to be pretreated-i.e., heated to several hundred ${ }^{\circ} \mathrm{C}$ under suitable gas flow. Afterwards, because of their large surface area, the particles are highly reactive and traces of, for instance, oxygen can oxidize them. To all EXAFS studies it is beneficial to decrease thermal disorder by lowering the temperature of the sample to $77 \mathrm{~K}$ during the EXAFS measurements. From these considerations it is apparent that the sample containing part of a versatile in situ EXAFS cell must be gastight, resistant to aggressive gases and should have the possibility to heat the sample to $700 \mathrm{~K}$ in a controlled fashion and to cool it down to $77 \mathrm{~K}$. Evacuation of the cell should be possible for measurements under vacuum or to quickly remove air before sample treatment. Finally the cell must be transparent for the incoming and transmitted $\mathrm{x}$-ray beam.
An EXAFS measurement may take several hours so the sample must stay at liquid nitrogen temperature over such a iong period of time without interruption of the experiment. At most synchrotron sites the laboratory where the pretreatments are done is not near the radiation controlled areas where the EXAFS experiments are performed. Therefore the cell should be easily transportable.

In the past several in situ EXAFS cells have been reported, ${ }^{i-4}$ some of which are commercially available. None of these meet all the above mentioned requirements. The cell reported by Lytle et al. ${ }^{1}$ uses a boron nitride or beryllium boat which holds the powdery sample. Gas is passed directly through the sample. Unfortunately, loose powciers are likely to contain pinholes which form radiation leaks. As was pointed out by Stern and $\mathrm{Kim}^{5}$ this will result in distortion of the experimental data. Some of the designs ${ }^{1,2}$ use Mylar xray windows which are not oxygen tight, while others ${ }^{3}$ have dynamic $O$ ring seals which introduce possible leaks. In the Clausen cell the temperature of the sample itself is not monitored and during measurement the thermal contact to the cooled brass part is not ensured.

It was therefore necessary to develop a new type of transmission cell in which a catalytic sample-pressed in a 


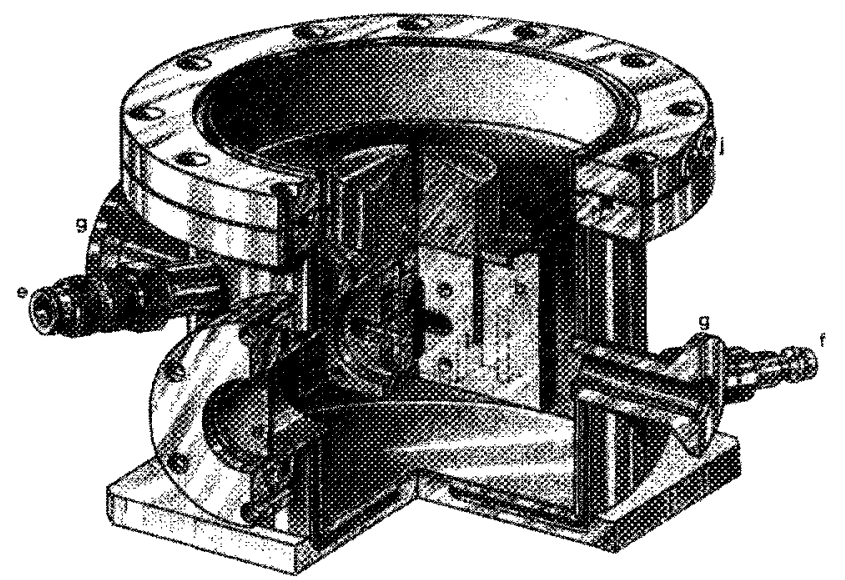

FIo. 1. The transmission cell. (a) Samplc holder, (b) aluminum samplemount, (c) copper heat conductor, (d) Be window, (e) water outlet, (f) water inlet, ( $g$ ) gas in-foutlets, (h) 0 rings, (i) thermocouple, (j) thermocouple connections.

selfsupporting wafer-could be heated up to $500^{\circ} \mathrm{C}$ in a controlled manner under a constant flow of gas (including $\mathrm{H}_{2}$, $\mathrm{O}_{2}, \mathrm{CO}$, and $\mathrm{H}_{2} \mathrm{~S}$ ) and kept at that temperature for several hours. The cell must be vacuum tight-but more important-gas tight up to the ppm level when operated under atmospheric pressure. Sample changement should be easily performed. The cell must have the possibility to operate with a horizontal (synchrotron radiation) and vertical (conventional $x$-ray tube) beam. During the EXAFS measurement it must be possible to cool the sample down to liquid nitrogen temperature $(77 \mathrm{~K})$ and keep it there for several hours without interference. And last but not least the cell must be transparent for $x$ rays in the energy range above $4 \mathrm{keV}$.

\section{DESCRIPIION}

The transmission EXAFS cell consists of a cylindrical stainless steel compartment of $72 \mathrm{~mm}$ inside diameter and 90 $\mathrm{mm}$ height which is both used for treatment of the sample and for the actual EXAFS measurement (Fig. 1). It has two beryllium windows for the incoming and outgoing radiation. The $0.2-\mathrm{mm}$-thick windows have a diameter of $18 \mathrm{~mm}$ and are soldered in KF 25 flanges to make them easily exchangeable. Two KF 10 fianges are provided to connect gas flow apparatus and/or vacuum pumps etc. The compartment is accessible from the top.

The lid which seals the compartment holds the sample. Normally the sample is a pressed selfsupporting wafer held in the rectangular $\left(4 \times 18 \mathrm{~mm}^{2}\right)$ hole of a disk-shaped stainless-steel sample holder (diameter of $24 \mathrm{~mm}$ ). Two types of sample holders are used: one with a thickness of $4 \mathrm{~mm}$; the other of $8 \mathrm{~mm}$ for high-energy experiments. The sample holder is clamped into an aluminum sample support that is part of the lid. A cross-shaped recess allows the beam through. With a horizontal beam the sample is mounted horizontally, with a vertical beam vertically.

Thermal conduction through the lid is used to heat the sample or to cool it down to liquid nitrogen temperature. For this purpose the center part of the lid is made of copper which on the inside of the cell is in close heat contact with the aluminum sample mount. The copper-which during treatment will be heated in air to several hundred ${ }^{\circ} \mathrm{C}$-is nickel plated to avoid corrosion. Since copper could not be made resistant to $\mathrm{H}_{2} \mathrm{~S}$ aluminum was used for the heat conductor on the inside of the cell. Aluminum has a good thermal conductivity and a special anodization treatment is available which makes it resistant to aggressive gases, like $\mathrm{O}_{2}$ and $\mathrm{H}_{2} \mathrm{~S}$. A K-type thermocouple close to the sample monitors its temperature and is used for feedback to temperature controllers. The outer ring of the lid is a flange with a diameter of $108 \mathrm{~mm}$ with which it is bolted to the corresponding flange of the body. An $O$ ring seals the compartment from air. To limit heat conduction from the copper to the flange the interconnecting ring is made of thin-walled stainless steel.

Beryllium and to a lesser extent $O$ rings cannot resist high temperature. At $80^{\circ} \mathrm{C}$ beryllium will react with oxygen to form the porous and highly toxic $\mathrm{BeO}$. It is therefore essential that the parts of the cell that incorporate these elements are cooled during the heating process. For this reason the cylindrical wall and the bottom of the cell are hollow and

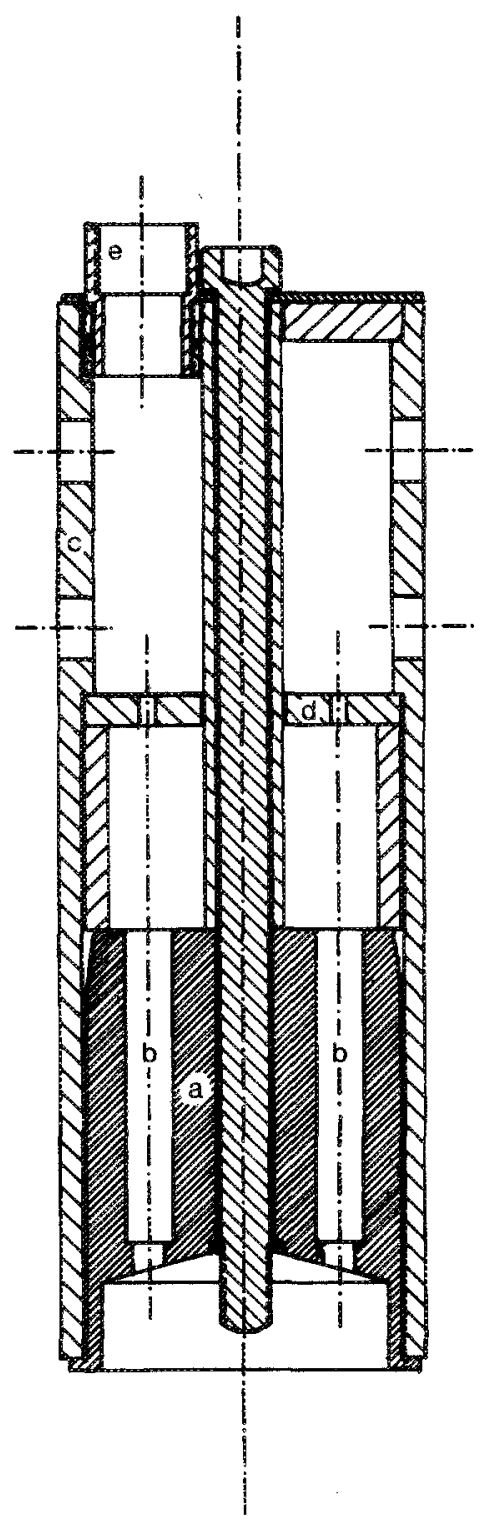

Fig. 2. Sectional view of the heater. (a) Copper heatconductor, (b) heater cartridge, (c) ceramic shielding, (d) ceramic heat shield, (e) Electrical feedthrough. 
water is flown through them. During the measurement when the cell is cooled down to liquid nitrogen temperature the water fiow is used to keep the body of the cell above freezing point, thus preventing the formation of ice on the windows and keeping the $O$ rings flexible. Snap-on water couplings ensure easy transferability from the laboratory environment to the EXAFS experimental area.

To be able to heat the sample to $500^{\circ} \mathrm{C}$ in a heat conductive atmosphere (e.g., $\mathrm{H}_{2}$ ) a high-power heater was developed. It consists of a copper body in which four heater cartridges are fitted and which can be attached to the heat conductive copper cylinder of the lid of the cells (Fig. 2). The cartridges are commercially available 200 -W high-temperature mould heaters. To ensure heat contact with the copper, the cartridges are inserted using a suspension of silver grains. A ceramic housing is used to minimize heatioss by convection and radiation and to shield the electrical connections from the heat. Like the copper part of the lid, the copper of the heater is nickel plated to prevent the formation of an oxide crust which inhibits heat transfer to the cell. Commercially available temperature programmers/controllers (e.g., Eurotherm) can easily be adjusted for the use in combination with the heater.

To cool the sample down to $77 \mathrm{~K}$ a liquid nitrogen container can be fitted to the copper cylinder of the lid. It consists of a polystyrene bucket which can contain about $10 l$ of liquid nitrogen (Fig. 3). A copper heat conductor which is in direct heat contact with the contents of the container, sticks through the bottom of the polystyrene container. The container can be placed on top of the cell with the copper attached to the copper cylinder of the lid. When totally filled with liquid nitrogen the system can keep the sample at $77 \mathrm{~K}$ for $4-5 \mathrm{~h}$. If there is not enough room for the container inside the radiation shielded area of the EXAFS experiment a small heat exchanger can be used instead. It is similarly attached to the heat conductive body of the cell. By means of a pressurized dewar vessel liquid nitrogen can flow through this device to cool the sample.

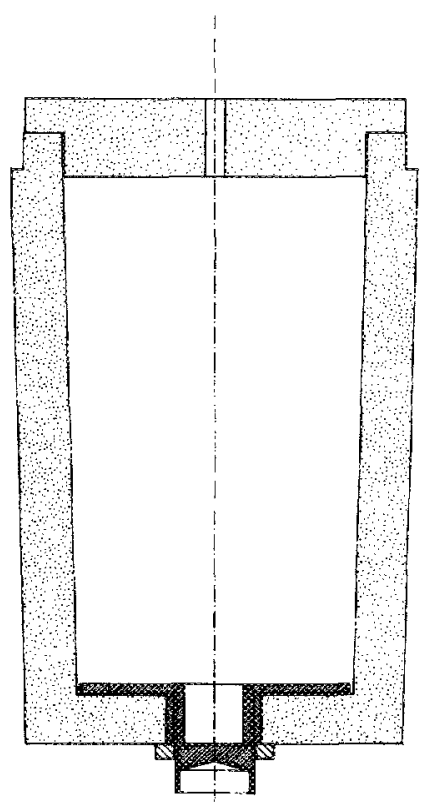

FIG. 3. Sectional view of the liquid nitrogen container. (close hatched area): copper; (dotted area): polystyrene; (hatched area): Stainless steel.

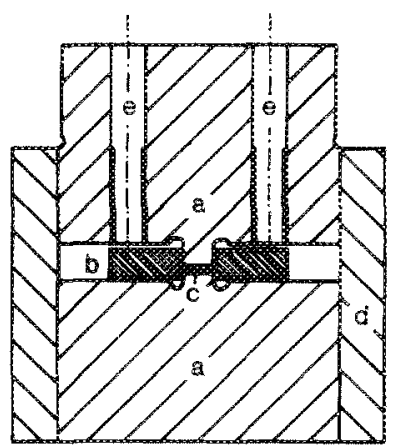

FIG. 4. Sectional view of the set of dies with sample holder. (a) Die, (b) sample holder, (c) sample powder, (d) die guide and (e) holes to facilitate sample detachment.

To avoid pirholes-which lead to loss of EXAFS amplitude -in powdery samples it is necessary to measure them as selfsupporting wafers pressed in a sample holder. A specially designed combination of dies is used to press the sample in the rectangular recess of $4 \mathrm{~mm}$ by $18 \mathrm{~mm}$ of the sample holder (Fig. 4). Parallelness of the die surfaces is essential to avoid non-uniformity of the pressed wafer. To ensure this the dies are guided by a stainless steel cylinder which maintains the orientation of the dies relative to each other. The dies can be used with any ordinary hydraulic press.

\section{OISCUSSION}

The cell has been tested under normal operating conditions. In a flow of $100 \mathrm{cc} / \mathrm{min}_{2}$ the sample can be heated to a maximum temperature of $500^{\circ} \mathrm{C}$. The actual sample temperature has been tested with a second thermocouple embedded in a dummy sample made from a special type of cement with thermal properties comparable to actual samples. This showed that over the full temperature range, the temperature of the sample was within $5^{\circ} \mathrm{C}$ of the temperature monitored by the measuring thermocouple inside the aluminum sample mount (Fig. 5). Wish a third thermocouple clamped to one of the transmission beryllium windows the temperature of the beryllium was checked. At $500^{\circ} \mathrm{C}$ sample temperature in a flowing $\mathrm{H}_{2}$ atmosphere the center of the window was about $30^{\circ} \mathrm{C}$, which is well below the temperature at which oxidation and the formation of the toxic BeO occurs.

The performance of the heaters was tested in a life test in

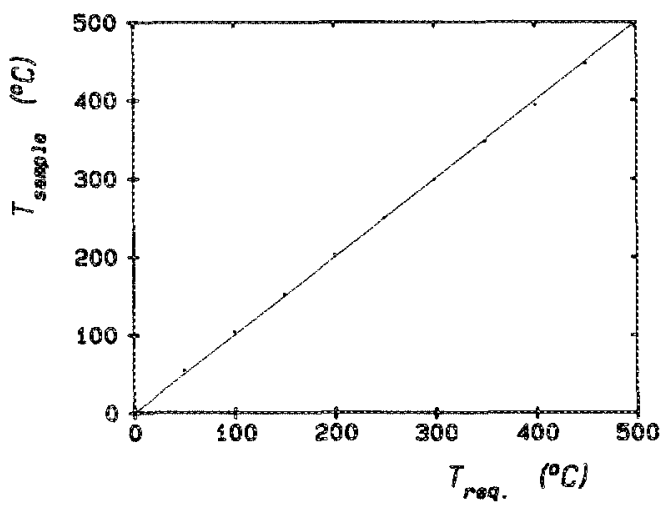

Fig. 5. Temperature of the wafer vs requested temperature. Measurement was done in a transmission cell with a hydrogen flow of $100 \mathrm{cc} / \mathrm{min}$ using an Eurotherm temperature programmer. 
combination with the transmission cell over several weeks with a continuous cycle of heating with $10^{\circ} \mathrm{C} / \mathrm{min}$ to a sample temperature of $450^{\circ} \mathrm{C}$, dwell period of $5 \mathrm{~h}$ at $450^{\circ} \mathrm{C}$ and cooling down with $10^{\circ} \mathrm{C} / \mathrm{min}$. To aggravate conditions only two heater cartridges were in use and no ceramic shielding was employed. Breakdown had not occurred after 25 days. To test the heat conduction of the parts in between heater and sample, the temperature of a heater was measured. At a sample temperature of $450^{\circ} \mathrm{C}$ the average temperature of the copper block of the heater was $550^{\circ} \mathrm{C}$.

To heat the sample by means of conduction of the heat through the lid is very advantageous. It is virtually foolproof; there are no electrical feed throughs into the cell which are possible causes of leakage; the heater can be used for another cell while the treated sample is being measured and in the unlikely event of a heater breakdown the sample can remain inside the cell and a replacement heater can be used to finish the treatment. Using a parallel connection of the four heater cartridges decreases the chance of a heater breakdown since-as has been shown above--even with two working cartridges a sample temperature of $450^{\circ} \mathrm{C}$ can be reached. The disadvantage of heat conduction is a large time constant in the temperature controller feedback loop. However, if the settings of the temperature controller have been optimized, the difference between the requested temperature and the actual temperature of the sample does not exceed $\pm 5^{\circ} \mathrm{C}$.

The $\mathbb{K}$-type thermocouple has the advantage that it is most commonly used and that most equipment can be made compatible with it. Unfortunately it is not very well suited for cryogenic temperatures. If this temperature range is of importance to the experimenter, a different type couple should be mounted.

Since leaktightness is a prerequisite of an EXAFS in situ cell used in catalytic research, the cell was leak tested under vacuum with standard leak testing equipment (Varian 93665). No leaks could be detected, which implies leak rates below $10^{-11} \mathrm{cc} / \mathrm{min}$. Under atmospheric pressure extremely oxygen sensitive samples ${ }^{6}$ have been loaded in the transmission cell and kept for days before EXAFS measurement. No oxidation was observed in the spectra.

Several catalytic research groups have tested the transmission cell extensively over the last two years, at different synchrotron sites. ${ }^{6-12}$ The transmission cell has been used with $\mathrm{He}, \mathrm{H}_{2}, \mathrm{O}_{2}, \mathrm{H}_{2} \mathrm{~S}$, and $\mathrm{CO}$ and under vacuum at high and low $\left(\mathrm{BN}_{2}\right)$ temperatures without any damage or corrosion being apparent.

\footnotetext{
a) To whom correspondence should be addressed.

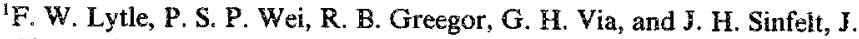
Chem. Phys. 70, 4849 (1979).

${ }^{2}$ F. W. Lytie, R. B. Greegor, E. C. Marques, D. R. Sandstrom, G. H. Via, and J. H. Sinfelt, in Catal. 95, 546 (1985).

${ }^{3}$ D. C. Koningsberger and J. W. Cook, Ir., in EXAFS and Near Edge Structure, Vol. 27 of Chemical Physics, edited by A. Bianconi, L. Incoccia, and S. Stipcich (Springer, Berlin, 1983), p. 412.

${ }^{4}$ B. S. Clausen, B. Lengeler, R. Candia, J. Als-Nieisen, and H. Topsøe, Bull, Soc. Chim. Belg. 90, 1249 (1981)

${ }^{5}$ E. A. Stern and X. Kim, Phys. Rev. B 23, 3781 (1981).

${ }^{5}$ A. S. Fung, P. A. Tooly, M. R. McDevitt, B. G. Gates, D. C. Koningsberger and M. J. Kelly. Preprints, Div. of Petrol. Chem., ACS, 33, 591 (1988),

${ }^{7}$ D. C. Koningsberger, F. B. M. Duivenvoorden, B. I. Kip, and D. E. Sayers, in EXAFS and Near Edge Structure IV, edited by P. Lagarde, D. Raoux, and J. Petiau (Les Editions de Physique, Les Ulis. Cedex, 1986), pp. C8-255.

${ }^{8}$ S. M. A. M. Bouwens, D. C. Koningsberger, V. H. J. de Beer, and R. Prins, Bull. Soc. Chim. Belg. 96, 951 (1987).

'J. H. A. Martens, R. Prins, H. Zandbergen, and D. C. Koningsberger, J. Phys. Chem. 92, 1903 (1988)

${ }^{10}$ F. B. M. van Zon, G. J. Visser, and D. C. Koningsberger, in Proceedings of the 9 th International Congress on Catalysis, Calgary, 1988, edited by M. J. Phillips and $M$. Ternan (The Chemical Institution of Canada, Ottawa, 1988), Vol. 3, p. 1386.

"S. M. A. M. Bouwens, D. C. Koningsberger, V. H. J. de Beer, and R. Prins, Catal. Lett. 1, 55 (1988).

${ }^{12}$ F. B. M. van Zon, thesis, Eindhoven University of Technology, 1988.
} 